\title{
Use of physician-recommended non-pharmacological strategies for hypertension control among hypertensive patients
}

\author{
Xuefeng Liu PhD ${ }^{1,2}$ (D) | James Brian Byrd MD, MS ${ }^{3}$ | Carlos J. Rodriguez MD, MPH ${ }^{4,5}$ (C)
}

${ }^{1}$ Department of Systems, Populations, and Leadership, University of Michigan, Ann Arbor, MI, USA

${ }^{2}$ Frankel Cardiovascular Center, University of Michigan School of Medicine, Ann Arbor, MI, USA

${ }^{3}$ Division of Cardiovascular

Medicine, University of Michigan Health

System, Ann Arbor, MI, USA

${ }^{4}$ Division of Public Health

Sciences, Department of Epidemiology, Wake

Forest School of Medicine, Winston-Salem, NC, USA

${ }^{5}$ Department of Internal Medicine (Cardiology), Wake Forest School of Medicine, Winston-Salem, NC, USA

\section{Correspondence}

Xuefeng Liu, PhD, Department of Systems, Populations, and Leadership, University of Michigan, Ann Arbor, MI, USA.

Email: liuxf@med.umich.edu
This study aims to evaluate the 4 non-pharmacological strategies adopted by patients for hypertension control and patient characteristics that affect the choice of strategies. Four thousand hypertensive patients aged $\geq 18$ years were selected from the National Health and Nutrition Examination Survey. Odds ratios of the choice of strategies were analyzed using weighted logistic models. Clinical recommendations of nonpharmacological strategies for hypertension control were relatively low. More exercise was the least frequent strategy used for hypertension control. More patients reported using $\geq 3$ strategies than using $\leq 2$ strategies ( $79.1 \%$ vs $20.9 \%, P<.0001$ ). Non-Hispanic blacks were more likely to use each individual strategy and to use $\geq 3$ strategies simultaneously. Patients with obesity and diabetes were less likely to attempt weight control or more exercise, but more likely to use $\geq 3$ strategies than peers. Educational programs should be developed to enhance physician's advice for lifestyle modifications and to increase patient's acceptance of physical activity.

\section{1 | INTRODUCTION}

High blood pressure (BP) or hypertension is a chronic medical disorder that affects 85.7 million adults in the United States (US). ${ }^{1}$ It is a major risk factor for adverse cardiovascular and renal diseases. ${ }^{2-5}$ While drug therapies have provided the capability for lowering BP in persons with hypertension, ${ }^{6}$ hypertension remains a major public health concern and about half of hypertensive individuals do not have their BP controlled below 140/90 mm Hg. ${ }^{7,8}$

Beyond antihypertensive drugs, numerous non-pharmacological strategies have been assessed and recommended to improve BP control. ${ }^{9-11}$ Intervention trials show that several self-managed strategies, including weight loss ${ }^{12,13}$; reduced sodium intake ${ }^{14}$; increased fruit, vegetable, ${ }^{15}$ and potassium intake ${ }^{16}$; reduced alcohol intake ${ }^{17}$; and moderate or vigorous physical activity ${ }^{13}$ are efficacious in lowering BP. These strategies play a major role in cardiovascular prevention and treatment through effects on $\mathrm{BP}$, and have been recommended by the American Heart Association and endorsed by the American Society of Hypertension for preventing the adverse health consequences of hypertension. ${ }^{15}$ However, the significant efficacy of strategies does not necessarily translate into patients' adoption of them for lowering BP. How commonly these strategies are adopted and whether one strategy is more frequently used than the alternative ones for selfmanagement of BP have not been evaluated among hypertensive patients in the US. Knowledge of which specific strategies are frequently adopted, along with the factors that affect the choice of strategies may inform efforts to improve non-pharmacological interventions directed at lowering $\mathrm{BP}$.

In this study, individuals of age 18 years or over with a diagnosis of hypertension were selected from the US National Health and Nutrition Examination Survey (NHANES). Among the patients whose physicians had recommended non-pharmacologic strategies, the adoption rate of each strategy and the number of strategies adopted by hypertensive patients after the recommendation were calculated. In addition, the characteristics associated with the number of adopted strategies were identified. The findings would be critical for informing physicians' 
recommendations regarding non-pharmacologic therapies of hypertension as an aide to drug therapy, allowing physicians to guide patients toward lifestyle modifications they are more likely to adopt.

\section{2 | METHODS}

\section{1 | Survey design}

National Health and Nutrition Examination Survey is a series of 2-year national surveys conducted by the Centers for Disease Control and Prevention National Center for Health Statistics (NCHS). ${ }^{18}$ It is designed to monitor the health and nutrition status among children and adults in the US. Participants in each survey were randomly selected from 30 counties across the country using a complex stratified multistage clustered sampling design, representative of the US civilian noninstitutionalized population. The surveys consisted of interviews and examinations. Face-to-face interviews were conducted in the participants' home to collect information for socio-demographic factors and history of diseases. Examinations were performed in mobile examination centers to obtain measurements of examination and clinical/ laboratory factors. All participants provided informed consent and the data were approved by the NCHS Institutional Review Board to ensure confidentiality. NCHS strictly complies with the federal laws to safeguard against releasing information that could identify a participant or a participant's family to anyone else without participants' consent (https://www.cdc.gov/nchs/data/nhanes-Is/nhanes_confidentiality_ brochure.pdf). The shared data in NHANES are de-identified in the sense that all information that could identify the participant and his/ her family has been removed.

\section{2 | Study population}

In the present study, hypertensive patients with data on nonpharmacologic strategies were selected from the NHANES 19992004. We only included individuals from 1999-2004 because information for non-pharmacologic strategies was not available in the other NHANES periods. There were 31070 individuals interviewed or examined in NHANES 1999-2004; among them, there were 4008 patients with a diagnosis of hypertension (see the definition below) who reported that a doctor had recommended at least one of the following non-pharmacologic strategies: weight loss, reduced sodium intake, reduced alcohol use, or moderate or vigorous physical activity as an adjunct to anti-hypertensive therapy. Those patients aged $<18$ years $(n=8)$ were excluded since this study focused on adults aged $\geq 18$ years with diagnosed hypertension. Thus, a total of 4000 -hypertensive patients, aged $\geq 18$ years were included in the study for further analysis.

\section{3 | Blood pressure measurements and hypertension definition}

Blood pressure in NHANES 1999-2004 was measured by trained physicians using mercury sphygmomanometry with appropriately sized arm cuffs after participants sat and rested for 5 minutes. ${ }^{19}$ Individuals aged $\geq 18$ years without recorded BP were excluded $(n=833)$. Following the American Heart Association recommendations that a minimum of 2 BP readings should be taken and the average of those readings be used to represent the patient's $\mathrm{BP},{ }^{20}$ up to $4 \mathrm{BP}$ readings were taken for measurement accuracy in NHANES. We followed the NHANES physician examination procedures manual to calculate the average BP for each participant. ${ }^{19}$ In determining mean BP for individuals, the first $\mathrm{BP}$ was used if only 1 measurement was obtained. The second BP was used if 2 readings were taken; the mean of the last 2 or 3 values were used when 3 or 4 readings were available. ${ }^{7,19,21}$ The percentage of individuals with 3 systolic BP readings was $80.7 \%$ in 1999-2004. The percentage of individuals with 1 systolic BP was $7.4 \%$ in 1999-2004. The percentage of individuals with 3 diastolic readings was $0.6 \%$ lower than for systolic $\mathrm{BP}$ and the percentage of individuals with 1 measurement was $0.1 \%$ higher.

Participants were defined as having hypertension if their mean systolic BP was at least $140 \mathrm{~mm} \mathrm{Hg}$, mean diastolic BP at least $90 \mathrm{~mm} \mathrm{Hg},{ }^{22}$ or both, and/or if they were currently taking prescription medication to lower BP. ${ }^{7,23}$

\section{4 | Non-pharmacologic strategies}

In this study, the strategies investigated as adjuncts to antihypertensive therapy included weight loss, reduced sodium intake, reduced alcohol use, and moderate or vigorous physical activity. They were assessed via the questionnaire components in the NHANES survey. Participants with a diagnosis of hypertension were first asked the following questions: "Have you been told by a doctor to control weight for hypertension control?" "Have you been told by a doctor to reduce sodium intake for hypertension control?" "Have you been told by a doctor to exercise more for hypertension control?" And, "Have you been told by a doctor to reduce alcohol consumption for hypertension control?" Hypertensive patients who had been told by a doctor to use one or more of these strategies for BP control were also asked "Are you controlling weight or losing weight?" "Are you now cutting down on salt or sodium in your diet?" "Are you now exercising more?" And, "Are you now cutting down on alcohol consumption?" Whether a patient was adopting a specific non-pharmacologic strategy for hypertension control was determined by the response to the above questions.

\subsection{Patient characteristics}

\subsection{1 | Clinical factors}

High cholesterol was defined as serum total cholesterol of at least $199 \mathrm{mg} / \mathrm{dL}$. Serum cholesterol was measured enzymatically in a series of coupled reactions that hydrolyze cholesteryl esters and oxidize the 3-OH group of cholesterol, using a Beckman Synchron LX20. Diabetes was diagnosed as a glycohemoglobin ( $\mathrm{HbA1c}$ ) of at least $6.5 \%$ or use of insulin or diabetes pills to lower blood sugar. HbA1c was measured on computerized microprocessors (Model CLC330), which control all 
functions in a liquid chromatograph and computing integrator. The signal from a spectrophotometric detector was processed and the concentration of $\mathrm{HbA} 1 \mathrm{c}$ was calculated as a percentage of the total detected. High triglyceride was defined as the level of triglyceride of at least $150 \mathrm{mg} / \mathrm{dL}$.

\subsection{2 | Demographic and behavioral factors}

Information on age, gender, race/ethnicity, education, and family history of hypertension/stroke was self-reported via questionnaire components. Age was grouped into 18-39 years (young adults), 40-59 years (middle-aged adults), and 60 years or over (old adults). Race/ethnicity included non-Hispanic white, non-Hispanic black, Hispanic, and other. Education was classified as high school or below and college or above in terms of years in school. Poverty status was determined as poor if the family's poverty income ratio (PIR) was less than or equal to 1. PIR was calculated by dividing family total income by poverty threshold, which was a guideline specific to family size as well as the appropriate year and state, issued each year by the Department of Health and Human Services. Body mass index (BMI) was calculated as weight in kilograms divided by the squared height in meters, and obesity was defined as a BMI of at least $30 \mathrm{~kg} / \mathrm{m}^{2}$.

\section{6 | Statistical analysis}

Analytic and reporting guidelines for NHANES study were followed. ${ }^{24}$ Sampling designs and weights were incorporated into data analysis to reflect the unequal probability of selection, nonresponse adjustment, and adjustment to independent population controls and to increase the reliability of parameter estimates, including means, percentages, adoption rates, and odds ratios (ORs). Sampling weights were combined for multi-year samples by dividing two-year weights by the number of survey cycles. Sampling errors of estimates were calculated by using Taylor Series Linearization methods.

Means with 95\% confidence intervals (Cls) were calculated for continuous data and percentages and/or rates with $95 \% \mathrm{Cls}$ for categorical data. Survey $F$ tests were used to compare the means between groups and Rao-Scott chi-square tests were conducted for percentage or rate comparisons. The difference in means or percentages was reported to be significant if the $\mathrm{p}$-value calculated from the $t$ test or chi-square test was less than 0.05 .

The rate of each non-pharmacologic strategy that was recommended by physicians and used by patients was calculated as the weighted number of patients with the positive response (yes) to the strategy questions divided by the total weighted number of patients who answered the questions (yes or no) in the overall study population as well as in the groups defined by each characteristic. Individuals with "not sure" or "missing" response were excluded from the rate computation. The total number of strategies adopted by patients for hypertension control was determined based on the complete data for all the 4 investigated strategies. Weighted logistic regression models were conducted and ORs with $95 \%$ Cls were calculated to identify the factors related to the total number of strategies used by patients and to the preference of the strategy choice. Wald chi-square test was run to evaluate the significance of the factors in influencing the choice of strategies. Data analyses were performed on PC using SAS software (SAS Institute).

\section{3 | RESULTS}

The average age of hypertensive patients in the study was 59.8 years. $55 \%$ were females. $73.8 \%$ were non-Hispanic whites, $14.3 \%$ were nonHispanic blacks, and $7.9 \%$ were Hispanics. Hypertension was uncontrolled in $46.8 \%$ of patients. Patients who reported having been told by physicians to control weight, reduce sodium, exercise more, and/ or reduce alcohol use for hypertension control accounted for $55.6 \%$, $68.4 \%, 66.6 \%$, and $25.5 \%$, of the study population, respectively.

Compared to patients with controlled hypertension, patients with uncontrolled hypertension were older, less educated, and poorer and had lower BMI, higher total cholesterol level, and lower triglyceride level (Table 1). Patients with uncontrolled hypertension reported having received a physician's recommendation for non-pharmacological strategies less frequently than patients with controlled hypertension (weight control: $52.8 \%$ vs $58.2 \%, P=.037$; sodium reduction: $66.6 \%$ vs $69.9 \%, P=.0372$; more exercise: $61.0 \%$ vs $71.6 \%, P<.0001$; alcohol reduction: $22.8 \%$ vs $27.9 \%, P=.0004$ ).

Among hypertensive patients reporting a physician's recommendation to pursue at least 1 non-pharmacological strategy for hypertension control, the self-reported adoption rates of the 4 recommended strategies-weight control, reduction in sodium intake, more exercise, and reduction in alcohol use-were $76.8 \%, 86.7 \%, 58.8 \%$, and $76.8 \%$, respectively (Table 2 ). The most frequently reported strategy was sodium intake reduction (86.7\%), varying according to various patient characteristics, from $77.3 \%$ in young patients of age $18-39$ years to $91.8 \%$ in non-Hispanic black patients. The least frequently reported strategy was "more exercise" (58.8\%), and the rates of reporting the use of this strategy for hypertension control varied from $54.2 \%$ in patients with diabetes to $65.0 \%$ in patients without obesity. The rates at which participants reported undertaking weight control and alcohol use reduction were similar in the overall population and in each group of characteristics; weight control varied from $72.6 \%$ in the obese group to $84.9 \%$ in the non-obese group, and alcohol use reduction varied from $73.4 \%$ in non-Hispanic whites to $86.8 \%$ in Hispanics.

Middle-aged patients were 2.08 fold (OR, 2.08; 95\% Cl, 1.07-4.04) and old patients were almost 3 fold (OR, 2.99; $95 \% \mathrm{Cl}, 1.55-5.79$ ) more likely to report using sodium reduction for hypertension control compared to young patients. Female patients were $70 \%$ more likely than male patients to report undertaking sodium reduction as the strategy (Table 3). Compared to non-Hispanic whites, non-Hispanic black patients were $36 \%(\mathrm{OR}, 1.36 ; 95 \% \mathrm{Cl}, 1.05-1.75)$ more likely to undertake weight control, 145\% (OR, 2.45; 95\% Cl, 1.55-3.89) more likely to report using sodium reduction, $44 \%$ (OR, 1.44; $95 \% \mathrm{Cl}, 1.16$ 1.78) more likely to report undertaking more exercise, and $61 \%$ (OR, 1.61; $95 \% \mathrm{Cl}, 1.03-2.51$ ) more likely to report reducing alcohol use as one of the strategies for hypertension control. Hispanic patients 


\begin{tabular}{|c|c|c|c|}
\hline \multirow[b]{2}{*}{ Characteristics } & \multicolumn{3}{|c|}{ Percentages or means ( $95 \%$ confidence intervals) } \\
\hline & All & $\begin{array}{l}\text { Controlled } \\
\text { hypertension }\end{array}$ & $\begin{array}{l}\text { Uncontrolled } \\
\text { hypertension }\end{array}$ \\
\hline Count (N) & 4000 & 2130 & 1870 \\
\hline \multicolumn{4}{|l|}{ Age } \\
\hline Mean (y) & $59.8(59.1,60.5)$ & $59.0(58.1,59.9)$ & $60.8(59.7,61.8)^{* * *}$ \\
\hline $18-39(\%)$ & $7.7(6.2,9.2)$ & $6.8(5.5,8.0)$ & $8.8(6.2,11.4)$ \\
\hline $40-59(\%)$ & $40.8(38.6,43.1)$ & $44.8(41.4,48.2)$ & $36.5(33.3,39.6)^{* *}$ \\
\hline$\geq 60(\%)$ & $51.4(49.3,53.6)$ & $48.4(45.2,51.7)$ & $54.7(51.8,57.7)^{* * *}$ \\
\hline \multicolumn{4}{|l|}{ Gender } \\
\hline Female (\%) & $55.0(52.6,57.3)$ & $53.1(50.0,56.2)$ & $57.0(53.7,60.3)$ \\
\hline \multicolumn{4}{|l|}{ Race/Ethnicity } \\
\hline $\begin{array}{l}\text { Non-Hispanic } \\
\text { white (\%) }\end{array}$ & $73.8(69.7,77.9)$ & $76.5(72.6,80.3)$ & $70.9(66.2,75.6)$ \\
\hline $\begin{array}{l}\text { Non-Hispanic } \\
\text { black (\%) }\end{array}$ & $14.3(11.0,17.5)$ & $13.2(10.3,16.0)$ & $15.5(11.6,19.4)$ \\
\hline Hispanic (\%) & $7.9(4.9,10.9)$ & $6.9(4.0,9.9)$ & $9.0(5.7,12.4)$ \\
\hline \multicolumn{4}{|l|}{ Education } \\
\hline $\begin{array}{l}\text { High school or } \\
\text { below (\%) }\end{array}$ & $54.6(51.5,57.7)$ & $52.3(48.4,56.2)$ & $57.1(53.6,60.6)^{*}$ \\
\hline \multicolumn{4}{|c|}{ Family poverty income ratio } \\
\hline Mean & $2.9(2.8,3.0)$ & $3.0(2.9,3.1)$ & $2.7(2.6,2.9)^{* * *}$ \\
\hline Poor (\%) & $13.4(11.6,15.1)$ & $11.9(9.9,13.9)$ & $15.0(12.4,17.6)^{*}$ \\
\hline \multicolumn{4}{|l|}{ Body mass } \\
\hline Mean $\left(\mathrm{kg} / \mathrm{m}^{2}\right)$ & $30.9(30.6,31.3)$ & $31.4(30.9,31.9)$ & $30.5(30.0,31.0)^{* * *}$ \\
\hline Obesity (\%) & $48.3(46.3,50.3)$ & $50.4(47.3,53.4)$ & $46.0(42.5,49.5)$ \\
\hline \multicolumn{4}{|l|}{ Total cholesterol } \\
\hline Mean (mg/dL) & $208.1(205.9,210.3)$ & $204.5(201.2,207.9)$ & $212.1(209.6,214.6)^{* * *}$ \\
\hline $\begin{array}{l}\text { High cholesterol } \\
\text { (\%) }\end{array}$ & $56.4(53.8,59.1)$ & $52.9(49.2,56.6)$ & $60.4(57.3,63.5)^{* * *}$ \\
\hline \multicolumn{4}{|l|}{ Glycohemoglobin } \\
\hline Mean (\%) & $5.9(5.8,5.9)$ & $5.9(5.8,6.0)$ & $5.9(5.8,5.9)$ \\
\hline Diabetes (\%) & $15.4(13.9,16.9)$ & $16.1(14.0,18.2)$ & $14.6(12.6,16.7)$ \\
\hline \multicolumn{4}{|l|}{ Triglyceride } \\
\hline Mean $\left(\mathrm{kg} / \mathrm{m}^{2}\right)$ & $172.9(165.6,180.3)$ & $177.9(165.9,189.9)$ & $166.8(159.1,174.5)^{* * *}$ \\
\hline $\begin{array}{l}\text { High triglyceride } \\
\text { (\%) }\end{array}$ & $45.9(42.9,49.0)$ & $47.0(42.4,51.6)$ & $44.6(40.8,48.4)$ \\
\hline Family history (\%) & $40.5(38.1,42.8)$ & $42.6(39.5,45.8)$ & $38.1(35.1,41.1)^{*}$ \\
\hline $\begin{array}{l}\text { Told to control } \\
\text { weight (\%) }\end{array}$ & $55.6(53.6,57.7)$ & $58.2(54.9,61.5)$ & $52.8(49.4,56.1)^{*}$ \\
\hline $\begin{array}{l}\text { Told to reduce } \\
\text { sodium (\%) }\end{array}$ & $68.4(66.7,70.0)$ & $69.9(67.9,71.9)$ & $66.6(64.1,69.2)^{*}$ \\
\hline $\begin{array}{l}\text { Told to exercise } \\
\text { more (\%) }\end{array}$ & $66.6(64.4,68.7)$ & $71.6(69.3,73.8)$ & $61.0(57.6,64.4)^{* * *}$ \\
\hline $\begin{array}{l}\text { Told to reduce } \\
\text { alcohol (\%) }\end{array}$ & $25.5(23.5,27.5)$ & $27.9(25.3,30.5)$ & $22.8(20.6,25.1)^{* * *}$ \\
\hline
\end{tabular}

TABLE 1 Characteristics of hypertensive patients by hypertension control status in the study population $(n=4000)$

${ }^{*} P<.05,{ }^{* *} P<.01,{ }^{* * *} P<.001$ for overall differences in means or percentages of characteristics between patients with controlled hypertension and patients with uncontrolled hypertension. 
TAB LE 2 Self-reported adoption rates and 95\% confidence intervals of physician recommended non-pharmacological strategies for hypertension control among hypertensive patients $(n=3313)$

\begin{tabular}{|c|c|c|c|c|}
\hline Characteristics & Weight control & Reduced sodium intake & More exercise & $\begin{array}{l}\text { Reduced alcohol } \\
\text { use }\end{array}$ \\
\hline Count (n) & 1628 & 2503 & 1584 & 827 \\
\hline \multicolumn{5}{|l|}{ Age } \\
\hline $18-39(\%)$ & $74.5(64.1,84.8)$ & $77.3(67.6,87.1)$ & $55.3(43.1,67.6)$ & $77.6(64.9,90.4)$ \\
\hline$\geq 60(\%)$ & $77.7(73.7,81.7)$ & $89.5(87.2,91.8)$ & $60.2(57.4,63.0)$ & $75.4(70.4,80.4)$ \\
\hline \multicolumn{5}{|l|}{ Gender } \\
\hline Female (\%) & $75.6(71.7,79.4)$ & $90.2(88.2,92.1)$ & $57.1(54.0,60.1)$ & $79.7(74.2,85.3)$ \\
\hline Male (\%) & $78.1(73.4,82.9)$ & $82.6(79.0,86.2)$ & $60.8(56.8,64.9)$ & $74.8(68.5,81.1)$ \\
\hline \multicolumn{5}{|l|}{ Race/Ethnicity } \\
\hline \multicolumn{5}{|l|}{ Education } \\
\hline High school or below (\%) & $76.0(71.9,80.0)$ & $86.4(83.6,89.3)$ & $58.2(54.6,61.9)$ & $76.3(70.1,82.4)$ \\
\hline College or above (\%) & $77.6(73.3,82.0)$ & $87.0(83.7,90.4)$ & $59.3(56.0,62.6)$ & $77.6(71.7,83.4)$ \\
\hline \multicolumn{5}{|l|}{ Family poverty income ratio } \\
\hline Poor (\%) & $76.8(68.7,84.9)$ & $85.9(81.2,90.7)$ & $55.7(49.2,62.2)$ & $81.9(72.1,91.6)$ \\
\hline Non-poor (\%) & $76.8(72.6,80.9)$ & $86.2(83.8,88.6)$ & $60.0(57.0,63.0)$ & $75.6(70.5,80.8)$ \\
\hline \multicolumn{5}{|l|}{ Body mass index } \\
\hline Obesity (\%) & $72.6(68.3,77.0)$ & $85.8(83.3,88.4)$ & $54.5(51.2,57.8)$ & $77.2(70.8,83.6)$ \\
\hline Non-diabetes (\%) & $77.4(73.6,81.2)$ & $85.9(83.5,88.4)$ & $60.1(57.5,62.7)$ & $76.5(71.2,81.8)$ \\
\hline \multicolumn{5}{|l|}{ Triglyceride } \\
\hline High triglyceride (\%) & $76.9(72.1,81.8)$ & $87.0(82.6,91.4)$ & $54.4(49.6,59.1)$ & $75.8(67.5,84.2)$ \\
\hline Normal (\%) & $78.1(71.8,84.3)$ & $86.9(82.4,91.5)$ & $62.6(57.9,67.3)$ & $77.7(69.5,85.9)$ \\
\hline Family history (\%) & $76.1(70.8,81.4)$ & $86.9(83.6,90.2)$ & $57.5(52.6,62.4)$ & $77.5(70.7,84.3)$ \\
\hline
\end{tabular}

were $87 \%$ more likely to report using sodium reduction for BP control. Obese patients were $48 \%$ (OR, 52\%; $95 \% \mathrm{Cl}, 0.39-0.69)$ less likely to report undertaking weight control and $30 \%(\mathrm{OR}, 0.70$; $95 \% \mathrm{Cl}, 0.52-$ 0.94) less likely to report undertaking more exercise than patients without obesity. The likelihood of reporting taking more exercise for hypertension control decreased by $22 \%$ (OR, 0.78; $95 \% \mathrm{Cl}, 0.60-1.01$ ) in patients with diabetes compared to non-diabetic patients.

Among hypertensive patients who reported having been told by doctors to undertake the 4 non-pharmacologic strategies, $79.1 \%$ of patients reported using 3 or more non-pharmacological strategies, $12.1 \%$ using 2 strategies, and $8.8 \%$ using only 1 strategy or not using any strategy for hypertension control (Table 4). The percentage of patients who reported using 3 strategies or more (range, 73.6\%$87.4 \%$ ) was significantly higher than the percentage of patients who reported using 2 strategies (range, 6.1\%-15.6\%) or the percentage who reported using 0 or 1 strategy (range, $2.6 \%-14.4 \%$ ) in the overall population $(P<.0001)$, as well as in each group defined by patient characteristics (all $P$ values $<.0001$ ).

Compared to non-Hispanic whites, non-Hispanic black patients were $50 \%$ more likely to report using 2 strategies and $82 \%$ more likely to report using 3 strategies or more for hypertension control; Hispanic patients were $83 \%$ more likely than white patients to report using 2 strategies and $124 \%$ more likely to report using 3 strategies or more (Table 5). Patients with obesity were $64 \%$ more likely to report using 
TAB LE 3 Impact of socio-demographic and clinical factors on self-reported choice of physician recommended non-pharmacologic strategies among hypertensive patients $(n=3313)$

\begin{tabular}{|c|c|c|c|c|c|c|c|c|}
\hline \multirow[b]{2}{*}{ Characteristics } & \multicolumn{2}{|c|}{ Weight control $(n=2085)$} & \multicolumn{2}{|c|}{$\begin{array}{l}\text { Reduced sodium intake } \\
(\mathrm{n}=2805)\end{array}$} & \multicolumn{2}{|c|}{ More exercise $(n=2579)$} & \multicolumn{2}{|c|}{$\begin{array}{l}\text { Reduced alcohol use } \\
(n=1022)\end{array}$} \\
\hline & OR & $95 \% \mathrm{Cl}$ & OR & $95 \% \mathrm{Cl}$ & OR & $95 \% \mathrm{Cl}$ & OR & $95 \% \mathrm{Cl}$ \\
\hline $40-59$ y & 1.36 & $0.78-2.38$ & $2.08^{*}$ & $1.07-4.04$ & 1.26 & $0.69-2.30$ & 1.31 & $0.58-2.98$ \\
\hline$\geq 60 y$ & 1.28 & $0.70-2.33$ & $2.99^{* *}$ & $1.55-5.79$ & 1.34 & $0.73-2.46$ & 1.33 & $0.57-3.14$ \\
\hline Female & 0.91 & $0.69-1.19$ & $1.70^{* * *}$ & $1.26-2.29$ & 0.85 & 0.67-1.09 & 1.30 & $0.88-1.91$ \\
\hline \multicolumn{9}{|c|}{ Race/Ethnicity (vs non-Hispanic white) } \\
\hline Non-Hispanic black & $1.36^{*}$ & $1.05-1.75$ & $2.45^{* * *}$ & $1.55-3.89$ & $1.44^{* * *}$ & $1.16-1.78$ & $1.61^{*}$ & $1.03-2.51$ \\
\hline Hispanic & 1.30 & $0.70-2.43$ & $1.87^{*}$ & $1.01-3.46$ & 1.40 & $0.89-2.22$ & 2.02 & $0.82-4.98$ \\
\hline \multicolumn{9}{|c|}{ Poverty status (vs non-poor) } \\
\hline Poor & 0.99 & $0.59-1.67$ & 0.80 & $0.50-1.28$ & 0.84 & $0.59-1.20$ & 1.28 & $0.68-2.42$ \\
\hline Obesity & $0.52^{* * *}$ & $0.39-0.69$ & 0.97 & $0.64-1.45$ & $0.70^{*}$ & $0.52-0.94$ & 1.06 & $0.68-1.67$ \\
\hline High cholesterol & 0.85 & $0.64-1.15$ & 0.83 & $0.59-1.17$ & 0.89 & $0.69-1.16$ & 0.79 & $0.54-1.15$ \\
\hline Diabetes & 0.87 & $0.64-1.18$ & 1.32 & $0.84-2.08$ & $0.78^{*}$ & $0.60-1.01$ & 1.11 & $0.63-1.94$ \\
\hline Family history & 0.87 & $0.58-1.31$ & 1.06 & $0.74-1.52$ & 0.98 & $0.75-1.29$ & 1.08 & $0.62-1.89$ \\
\hline
\end{tabular}

$\mathrm{Cl}$, confidence interval; OR, odds ratio.

${ }^{*} P<.05,{ }^{* *} P<.01,{ }^{* * *} P<.001$ for the impact of factors on the choice of non-pharmacological strategies among hypertensive patients.

2 strategies, and were $68 \%$ more likely to report using 3 strategies for BP control than non-obese patients. The likelihoods of reporting the use of 2 strategies and 3 strategies or more increased $66 \%$ and $62 \%$, in diabetic patients relative to non-diabetic patients, respectively.

\section{4 | DISCUSSION}

We investigated 4 non-pharmacological strategies for BP controlweight control, reduction in sodium intake, more exercise, and reduction in alcohol use, as self-reported by NHANES participants. These strategies can serve as initial treatment before the start of drug therapy and as an adjunct to medication in persons already on drug therapy. In hypertensive individuals with medication-controlled BP, these strategies can facilitate drug step-down and drug withdrawal in highly motivated individuals who achieve and sustain lifestyle changes. ${ }^{25}$ Although accumulating evidence reveals that these strategies have significant effects on reducing $\mathrm{BP},{ }^{11,13,26,27}$ our analysis shows that relatively few people report that these strategies have been recommended by physicians for hypertension control. Among hypertensive patients, $55.6 \%$ were told to control weight, $68.4 \%$ were told to reduce sodium intake, and $66.6 \%$ were told to exercise more and reduce alcohol use. The chance of reporting undertaking lifestyle modifications beyond medications for hypertension control is higher in patients who report receiving physician's advice than patients not reporting any advice. ${ }^{28}$ To the extent that a self-report is accurate, less frequent recommendations for lifestyle interventions represent a lost opportunity for BP reduction and control. Investigation of physician characteristics as predictors for prescribing non-pharmacological strategies is needed in order to improve hypertension control among hypertensive patients.

Among hypertensive patients who report having been told by physicians to take non-pharmacological strategies, more exercise was the least frequent self-reported strategy (58.8\%) used for hypertension control. Regular aerobic physical activity can facilitate weight loss, decrease $\mathrm{BP}$, and reduce the overall risk of cardiovascular disease. ${ }^{22,29} \mathrm{BP}$ may be lowered by 4-9 $\mathrm{mm} \mathrm{Hg}$ with moderately intense physical activity including brisk walking for 30 minutes a day, 5 days per week. ${ }^{22}$ Non-preference for undertaking more exercise for BP control necessitates new strategies to engage hypertensive patients in more physical activity to reduce BP and improve cardiovascular health outcomes. Among hypertensive patients who reported receiving advice, the proportion that reported choosing to take at least 2 non-pharmacological strategies was much higher than the proportion that reported using a single strategy ( $91.2 \%$ vs $8.8 \%)$. As judged by the self-reports, physician advice appears to be an effective motivator for undertaking hypertension-related non-pharmacological strategies in individuals with hypertension regardless of gender, race/ethnicity, or other characteristics.

Obese patients were more likely to report using at least 2 nonpharmacological strategies for hypertension control. Obesity is a major risk factor for hypertension treatment and control. ${ }^{7,30}$ Weight reduction may lower BP by $5-20 \mathrm{~mm} \mathrm{Hg}$ per $10 \mathrm{~kg}$ of weight loss in an overweight or obese individual. ${ }^{22}$ The DASH eating plan encompasses 
TAB LE 4 Percentages (95\% confidence intervals) of the total number of physician recommended non-pharmacological strategies adopted by hypertensive patients $(n=3313)$

\begin{tabular}{|c|c|c|c|}
\hline Characteristics & \multicolumn{3}{|c|}{ Total numbers of strategies used } \\
\hline Count (\%) & 239 (7.2\%) & 408 (12.3\%) & $2666(80.5 \%)$ \\
\hline \multicolumn{4}{|l|}{ Age } \\
\hline $18-39(\%)$ & $14.4(0.0,30.4)$ & $12.0(1.1,22.9)$ & $73.6(55.2,92.0)^{*}$ \\
\hline \multicolumn{4}{|l|}{ Gender } \\
\hline Female (\%) & $6.6(2.8,10.4)$ & $12.7(7.4,17.9)$ & $80.7(74.8,86.7)^{*}$ \\
\hline Male (\%) & $10.5(4.2,16.9)$ & $11.6(6.7,16.5)$ & $77.8(72.5,83.2)^{*}$ \\
\hline \multicolumn{4}{|l|}{ Race/Ethnicity } \\
\hline \multicolumn{4}{|l|}{ Education } \\
\hline High school or below (\%) & $10.5(5.8,15.2)$ & $15.1(9.9,20.3)$ & $74.4(69.9,79.0)^{*}$ \\
\hline College or above (\%) & $6.7(1.5,11.9)$ & $8.1(4.5,11.7)$ & $85.2(79.2,91.3)^{*}$ \\
\hline \multicolumn{4}{|l|}{ Family poverty income ratio } \\
\hline Poor (\%) & $7.4(1.0,13.7)$ & $13.1(4.5,21.8)$ & $79.5(68.7,90.3)^{*}$ \\
\hline Non-poor (\%) & $9.7(5.1,14.3)$ & $12.1(7.2,17.1)$ & $78.2(74.0,82.4)^{*}$ \\
\hline \multicolumn{4}{|l|}{ Body mass index } \\
\hline Obesity (\%) & $10.6(5.4,15.9)$ & $15.6(10.2,20.9)$ & $73.8(68.4,79.2)^{*}$ \\
\hline Non-obesity (\%) & $6.6(3.0,10.1)$ & $6.1(1.7,10.5)$ & $87.4(82.6,92.1)^{*}$ \\
\hline Non-diabetes (\%) & $9.6(5.1,14.0)$ & $11.5(6.5,16.6)$ & $78.9(74.9,82.9)^{*}$ \\
\hline \multicolumn{4}{|l|}{ Triglyceride } \\
\hline High triglyceride (\%) & $9.3(1.9,16.6)$ & $12.8(7.7,18.0)$ & $77.9(69.7,86.1)^{*}$ \\
\hline Normal (\%) & $6.6(1.8,11.4)$ & $10.4(2.8,18.1)$ & $83.0(73.9,92.1)^{*}$ \\
\hline Family history (\%) & $9.2(2.5,15.8)$ & $12.4(7.0,17.9)$ & $78.4(70.9,85.9)^{*}$ \\
\hline
\end{tabular}

${ }^{*} P<.001$ for the differences in rates between groups determined by the number of non-pharmacological strategies adopted by hypertensive patients.

a diet rich in fruits, vegetables, and low-fat dairy products and may lower body weight and thus lower BP by $8-14 \mathrm{~mm} \mathrm{Hg} .{ }^{31}$ Hypertension programs and studies might inform hypertensive patients with obesity to be more aware of their increased risks of uncontrolled BP and adverse cardiovascular outcomes, and to be more willing to undertake multiple strategies rather than a single strategy for BP control. However, our data also shows that obese patients were less likely to report undertaking weight control or more exercise as a strategy beyond medications. This indicates that obesity is not only a risk factor for resistance to hypertension treatment, but also a risk factor for nonadherence to physical activity recommended by physicians. The reason obese people report less preference for increasing their exercise for hypertension control remains unclear. One possible reason is that obesity is associated with many adverse health outcomes (eg, diabetes and heart disease with joint discomfort), and these outcomes might limit exercise tolerance in patients and hence predispose them to avoid physical activity as a BP control strategy. ${ }^{32}$ This explanation is also supported by the finding in this study that patients with diabetes were less likely to report undertaking weight control and more exercise for hypertension control.

Our analysis shows that Non-Hispanic blacks and Hispanics were more likely than non-Hispanic whites to report undertaking multiple non-pharmacological strategies $(\geq 2)$ for BP control. Compared to non-Hispanic whites, non-Hispanic blacks have higher prevalence and 


\begin{tabular}{|c|c|c|c|c|}
\hline \multirow[b]{2}{*}{ Characteristics } & \multicolumn{2}{|c|}{2 (vs 0 or 1 ) } & \multicolumn{2}{|c|}{3 or more (vs 0 or 1 ) } \\
\hline & OR & $95 \% \mathrm{Cl}$ & OR & $95 \% \mathrm{Cl}$ \\
\hline \multicolumn{5}{|l|}{ Age (vs 18-39 y) } \\
\hline $40-59$ y & 1.46 & $0.90-2.39$ & 1.27 & $0.73-2.20$ \\
\hline$\geq 60 y$ & 1.36 & $0.85-2.19$ & 0.99 & $0.61-1.60$ \\
\hline \multicolumn{5}{|l|}{ Gender (vs male) } \\
\hline Female & 0.87 & $0.65-1.16$ & 0.81 & $0.64-1.02$ \\
\hline \multicolumn{5}{|c|}{ Race/Ethnicity (vs non-Hispanic white) } \\
\hline Non-Hispanic black & $1.50^{*}$ & $1.05-2.13$ & $1.82^{* * *}$ & 1.44-2.29 \\
\hline Hispanic & $1.83^{*}$ & $1.16-2.89$ & $2.24^{* * *}$ & $1.41-3.57$ \\
\hline \multicolumn{5}{|l|}{ Education (vs college or above) } \\
\hline High school or below (\%) & 1.07 & $0.81-1.42$ & 1.00 & $0.77-1.30$ \\
\hline \multicolumn{5}{|l|}{ Poverty status (vs non-poor) } \\
\hline Poor & 0.93 & $0.66-1.32$ & 0.89 & $0.60-1.31$ \\
\hline Obesity & $1.64^{* * *}$ & $1.24-2.15$ & $1.68^{* * *}$ & $1.40-2.03$ \\
\hline High cholesterol & $0.80^{*}$ & $0.67-0.96$ & $0.77^{*}$ & $0.62-0.97$ \\
\hline Diabetes & $1.66^{*}$ & $1.12-2.44$ & $1.62^{* *}$ & $1.15-2.27$ \\
\hline Family history & 1.20 & $0.89-1.63$ & 1.20 & $0.91-1.58$ \\
\hline
\end{tabular}

TABLE 5 Impact of socio-demographic and clinical factors on the number of physician recommended nonpharmacological strategies adopted by hypertensive patients $(n=3313)$

$\mathrm{Cl}$, confidence interval; OR, odds ratio.

${ }^{*} P<.05,{ }^{* *} P<.01,{ }^{* * *} P<.001$ for the impact of factors on the number of non-pharmacological strategies adopted by hypertensive patients.

awareness of hypertension and lower hypertension control and are more likely to be under treatment. ${ }^{7,33,34}$ More awareness of the risk of uncontrolled BP among non-Hispanic blacks may be a motivator to take more lifestyle modification techniques beyond medications, following the clinical recommendations by physicians ${ }^{35}$ to improve BP control. Hispanics with hypertension have lower treatment and lower control rates than non-Hispanic whites. ${ }^{7,34}$ One possible reason for Hispanics to report using multiple strategies is that Hispanic patients were more likely to report receiving physician's advice for non-pharmacological strategies than non-Hispanic whites (39\% more for weight control, $32 \%$ more for sodium intake reduction, $57 \%$ more for more exercise, and $100 \%$ more for alcohol use reduction in this study). Another possible reason is that knowledge of increased risk of uncontrolled hypertension among Hispanic patients may also motivate them to take more strategies than non-Hispanic whites to control BP as non-Hispanic black patients did in this study.

Uncontrolled hypertension is significantly associated with age and older people have higher rates of uncontrolled hypertension compared to younger people. Although older patients should take strategies beyond anti-hypertensive treatment for hypertension control, our study indicates that middle-aged and old patients did not report using non-pharmacological strategies (except for sodium intake reduction), and/or use at least 2 strategies more frequently than young patients to control hypertension. This cannot be simply explained by the limited physical capacity in older patients. More attention should be paid on how to engage older people in using more available lifestyle modifications for BP control. Older patients were more likely to report undertaking sodium reduction in our study. This presents evidence that diet-related programs, such as the DASH $\operatorname{diet}^{31}$ and the Mediterranean $\operatorname{diet}^{36}$ might be more appropriate and more likely to be successful for older patients. These programs can help older people with hypertension improve BP control through eating healthy and losing weight. ${ }^{31,37}$ In the meantime, exercise related programs that are well suited for older people need to be more widely available.

The NHANES program includes a large survey sample with a stratified multi-stage sampling design, ensuring adequate power to obtain unbiased estimates. There are several limitations in this study. It is possible that self-reporting does not accurately reflect physicians' advice or patients' use of blood pressure reduction strategies (even the use of medications). For example, self-reported sodium intake has been found to correlate poorly with urinary sodium excretion. ${ }^{38}$ The issue of accuracy of a self-report is inherent to studies that ask for patients' perspectives. Irrespective of the accuracy of a self-report, the findings of our study provide valuable insight into the issue of physicians' advice and adoption of that advice-directly from the patient's perspective. BP measurements were obtained at a single time point may capture some patients without persistent hypertension. In clinical practice, it is preferable to rely upon blood pressure estimates separated in time. However, the reliability of the blood pressure estimate provided by the NHANES' protocol is greater than that obtained in routine clinical practice, since the average of up to 4 separate measurements was obtained under the same standardized conditions in each of the surveys. Race/ethnicity of the health care provider may impact the patient-provider relationship, ${ }^{39}$ which might have a significant impact on the recommendation of 
and adherence to the non-pharmacological strategies described in our study; however, health care provider racial/ethnic information was not captured in NHANES to evaluate such impact. Our definition of hypertension excluded hypertensive individuals with BP successfully controlled by physical activity, weight control, and other non-pharmacological techniques. Participants who have been diagnosed to have hypertension but are not receiving medications are not counted as hypertensive.

In conclusion, among hypertensive patients who reported having been told by physicians to undertake non-pharmacological strategies, a great majority of patients reported adopting multiple strategies $(\geq 2)$ for hypertension control. Physicians' clinical advice, as recalled by patients, appears to play an important role in the number of strategies patients report adopting. Sodium intake reduction was the most reported adopted strategy and "more exercise" was the least adopted strategy by self-reports. Non-Hispanic blacks and Hispanics were more likely to report using at least 2 strategies, and non-Hispanic blacks were also more likely to report taking each single strategy, whereas Hispanics were more likely to report choosing sodium reduction for BP control. Hypertensive patients with obesity and diabetes were less likely to report undertaking more exercise compared to the corresponding peers. Education programs should be developed to enhance physicians' ability to dispense effective advice for lifestyle modifications and to increase patients' engagement in physical activity.

\section{ACKNOWLEDGMENTS}

We thank the National Center of Health Statistics for the available NHANES survey data.

\section{CONFLICT OF INTEREST}

The authors declare no conflicts of interest in the present study.

\section{ORCID}

Xuefeng Liu (iD http://orcid.org/0000-0003-0845-9038

Carlos J. Rodriguez (iD http://orcid.org/0000-0003-0860-9008

\section{REFERENCES}

1. Benjamin EJ, Blaha MJ, Chiuve SE, et al. Heart disease and stroke statistics - 2017 update: a report from the American Heart Association. Circulation. 2017;135:e146-e603.

2. Dubow J, Fink ME. Impact of hypertension on stroke. Curr Atheroscler Rep. 2011;13:298-305.

3. Wong ND, Thakral G, Franklin SS, et al. Preventing heart disease by controlling hypertension: impact of hypertensive subtype, stage, age, and sex. Am Heart J. 2003;145:888-895.

4. Khush KK, Tasissa G, Butler J, McGlothlin D, De Marco T, ESCAPE Investigators. Effect of pulmonary hypertension on clinical outcomes in advanced heart failure: analysis of the Evaluation Study of Congestive Heart Failure and Pulmonary Artery Catheterization Effectiveness (ESCAPE) database. Am Heart J. 2009;157:1026-1034.
5. Sim JJ, Shi J, Kovesdy CP, Kalantar-Zadeh K, Jacobsen SJ. Impact of achieved blood pressures on mortality risk and end-stage renal disease among a large, diverse hypertension population. J Am Coll Cardiol. 2014:64:588-597.

6. Hering D, Esler MD, Krum H, et al. Recent advances in the treatment of hypertension. Expert Rev Cardiovasc Ther. 2011;9:729-744.

7. Egan BM, Zhao $\mathrm{Y}$, Axon RN. US trends in prevalence, awareness, treatment, and control of hypertension, 1988-2008. JAMA 2010;303:2043-2050.

8. Chow CK, Yusuf R, Kelishadi R. Prevention and control of hypertension in different countries - reply. JAMA. 2014;311:419-420.

9. Brook RD, Appel LJ, Rubenfire M, et al. Beyond medications and diet: alternative approaches to lowering blood pressure: a scientific statement from the American Heart Association. Hypertension. 2013;61:1360-1383.

10. Appel LJ. Nonpharmacologic therapies that reduce blood pressure: a fresh perspective. Clin Cardiol. 1999;22(7 suppl):III1-III5.

11. Wexler R, Aukerman G. Nonpharmacologic strategies for managing hypertension. Am Fam Physician. 2006;73:1953-1956.

12. Semlitsch $T$, Jeitler $K$, Berghold $A$, et al. Long-term effects of weightreducing diets in people with hypertension. Cochrane Database Syst Rev. 2016;3:CD008274.

13. Blumenthal JA, Sherwood A, Gullette EC, et al. Exercise and weight loss reduce blood pressure in men and women with mild hypertension: effects on cardiovascular, metabolic, and hemodynamic functioning. Arch Intern Med. 2000;160:1947-1958.

14. Aburto NJ, Ziolkovska A, Hooper L, Elliott P, Cappuccio FP, Meerpohl $J$ J. Effect of lower sodium intake on health: systematic review and meta-analyses. BMJ. 2013;346:f1326.

15. Eckel RH, Jakicic JM, Ard JD, et al. 2013 AHA/ACC guideline on lifestyle management to reduce cardiovascular risk: a report of the American College of Cardiology/American Heart Association Task Force on Practice Guidelines. Circulation. 2014;129 (25 supp 2):S76-S99

16. Aburto NJ, Hanson S, Gutierrez H, Hooper L, Elliott P, Cappuccio FP. Effect of increased potassium intake on cardiovascular risk factors and disease: systematic review and meta-analyses. BMJ. 2013;346:f1378.

17. Roerecke M, Kaczorowski J, Tobe SW, Gmel G, Hasan OSM, Rehm J. The effect of a reduction in alcohol consumption on blood pressure: a systematic review and meta-analysis. Lancet Public Health. 2017;2:e108-e120.

18. National Center for Health Statistics. The National Health and Nutrition Examination Survey (NHANES) 1999-2010 Data Files. http://www.cdc.gov/nchs/nhanes/nhanes_questionnaires.htm. Accessed June 16, 2016

19. National Health and Nutrition Examination Survey. Physician examination procedures manual (January 2003). https://www.cdc.gov/ NCHS/data/nhanes/nhanes_03_04/PE.pdf. Accessed April 5, 2010.

20. Pickering TG, Hall JE, Appel LJ, et al. Recommendations for blood pressure measurement in humans and experimental animals: part 1: blood pressure measurement in humans: a statement for professionals from the Subcommittee of Professional and Public Education of the American Heart Association Council on High Blood Pressure Research. Circulation. 2005;111:697-716.

21. National Health and Nutrition Examination Survey. Physician examination procedures manual (original 1999, revised 2000). http:// www.cdc.gov/nchs/nhanes/nhanes_01_02/physician_year_3.pdf. Accessed April 5, 2010.

22. Chobanian AV, Bakris GL, Black HR, et al. The Seventh Report of the Joint National Committee on prevention, detection, evaluation, and treatment of high blood pressure: the JNC 7 report. JAMA. 2003;289:2560-2572

23. Liu X, Rodriguez CJ, Wang K. Prevalence and trends of isolated systolic hypertension among untreated adults in the United States. J Am Soc Hypertens. 2015;9:197-205. 
24. National Center for Health Statistics, Centers for Disease Control and Prevention. National Health and Nutrition Examination Survey: analytic guidelines, 1999-2010. http://www.cdc.gov/nchs/data/nhanes/ analytic_guidelines_11_12.pdf. Accessed June 20, 2015.

25. Appel LJ. Lifestyle modification as a means to prevent and treat high blood pressure. J Am Soc Nephrol. 2003;14(7 suppl 2):S99-S102.

26. Sacks FM, Svetkey LP, Vollmer WM, et al. Effects on blood pressure of reduced dietary sodium and the Dietary Approaches to Stop Hypertension (DASH) diet. DASH-Sodium Collaborative Research Group. N Engl J Med. 2001;344:3-10.

27. Appel L, Brands MW, Daniels SR, et al. Dietary approaches to prevent and treat hypertension: a scientific statement from the American Heart Association. Hypertension. 2006;47:296-308.

28. Egede LE. Lifestyle modification to improve blood pressure control in individuals with diabetes: is physician advice effective? Diabetes Care. 2003;26:602-607.

29. Myers J. Cardiology patient pages. Exercise and cardiovascular health. Circulation. 2003;107:e2-e5

30. Egan BM, Zhao Y, Axon RN, Brzezinski WA, Ferdinand KC Uncontrolled and apparent treatment resistant hypertension in the United States, 1988 to 2008. Circulation. 2011;124:1046-1058.

31. Blumenthal JA, Babyak MA, Hinderliter A, et al. Effects of the DASH diet alone and in combination with exercise and weight loss on blood pressure and cardiovascular biomarkers in men and women with high blood pressure: the ENCORE study. Arch Intern Med. 2010;170:126-135.

32. Borlaug BA, Melenovsky V, Russell SD, et al. Impaired chronotropic and vasodilator reserves limit exercise capacity in patients with heart failure and a preserved ejection fraction. Circulation. 2006;114:2138-2147.
33. Cutler JA, Sorlie PD, Wolz M, Thom T, Fields LE, Roccella EJ. Trends in hypertension prevalence, awareness, treatment, and control rates in United States adults between 1988-1994 and 1999-2004. Hypertension. 2008;52:818-827.

34. Hajjar I, Kotchen TA. Trends in prevalence, awareness, treatment, and control of hypertension in the United States, 1988-2000. JAMA. 2003;290:199-206.

35. Mellen PB, Palla SL, Goff Jr DC, Bonds DE. Prevalence of nutrition and exercise counseling for patients with hypertension. United States, 1999 to 2000. J Gen Intern Med. 2004;19:917-924.

36. Willett WC, Sacks F, Trichopoulou A, et al. Mediterranean diet pyramid: a cultural model for healthy eating. Am J Clin Nutr. 1995;61(6 suppl):1402S-1406S

37. Estruch R, Martinez-Gonzalez MA, Corella D, et al. Effects of a Mediterranean-style diet on cardiovascular risk factors: a randomized trial. Ann Intern Med. 2006;145:1-11.

38. Gerber LM, Mann SJ. Inaccuracy of self-reported low sodium diet. Am J Hum Biol. 2012;24:189-191.

39. Schoenthaler A, Allegrante JP, Chaplin W, Ogedegbe G. The effect of patient-provider communication on medication adherence in hypertensive black patients: does race concordance matter? Ann Behav Med. 2012;43:372-382.

How to cite this article: Liu X, Byrd JB, Rodriguez CJ. Use of physician-recommended non-pharmacological strategies for hypertension control among hypertensive patients. J Clin

Hypertens. 2018;20:518-527. https://doi.org/10.1111/ jch.13203 